\title{
Reprint of: Renal and visceral protection in thoracoabdominal aortic surgery*
}

\author{
Muhammad Aftab, MD, and Joseph S. Coselli, MD
}

\begin{abstract}
Objectives: Open thoracoabdominal aortic aneurysm (TAAA) repair traditionally carries substantial perioperative morbidity and mortality, primarily from distal aortic ischemia. Advances in surgical techniques, adjuncts, and strategies have greatly improved outcomes.
\end{abstract}

\begin{abstract}
Methods: We analyzed outcomes of 1267 open consecutive TAAA repairs between January 2005 and September 2013. We provided cold crystalloid renal perfusion whenever the renal ostia were accessible; according to extent of repair, we selectively used left heart bypass and provided isothermic blood to the celiac axis and superior mesenteric artery. Repair was extensive (Crawford extent I and II) in 717 cases (57\%). Left heart bypass was used in $645(51 \%)$ cases, cold crystalloid renal perfusion in $987(78 \%)$, and isothermic visceral perfusion in $318(25 \%)$. Additional patient-specific surgical adjuncts included endarterectomy of renal or visceral vessels, open stent placement within these vessels, or use of both techniques; at least one was used in 447 repairs (35\%).
\end{abstract}

Results: Thirty-day survival was 95\% (1198/1267); overall operative mortality was 8\% (104/1267). Acute renal dysfunction occurred in $155(12 \%)$, renal failure requiring hemodialysis at hospital discharge in 84 $(7 \%)$, and bowel ischemia in $9(<1 \%)$. Extent II and III TAAA repairs carried the highest risks of postoperative renal dysfunction and renal failure requiring hemodialysis at hospital discharge.

Conclusions: Contemporary protective strategies allow open TAAA repair with substantially fewer renal and visceral ischemic complications. Although bowel ischemia is uncommon, renal failure remains a concern, especially in extent II and extent III TAAA repairs. Additional studies are needed to identify and improve renal protection strategies. (J Thorac Cardiovasc Surg 2015;149:S130-3)

Open repair of thoracoabdominal aortic aneurysm (TAAA) traditionally carries a formidable risk of perioperative morbidity and mortality, primarily as a result of distal aortic ischemia during repair. Although renal dysfunction after TAAA repair occurs in as many as $28 \%$ of patients, it necessitates postoperative dialysis in $4 \%$ to $11 \%$ of cases. ${ }^{1-5}$ Preoperative renal impairment and postoperative renal complications are commonly associated with worsened long-term survival ${ }^{6}$ and increased postoperative mortality. ${ }^{4-9}$ Although cases of nonrenal visceral and bowel ischemia after TAAA repair are fortunately uncommon, they have been associated with substantial

DOI of original article: http://dx.doi.org/10.1016/j.jtcvs.2014.06.072

* This article is a reprint of a previously published article. For citation purposes, please use the original publication details; J Thorac Cardiovasc Surg. 2014;148:2963-6.

From the Division of Cardiothoracic Surgery, Michael E. DeBakey Department of Surgery, Baylor College of Medicine, Houston, Tex; and the Department of Cardiovascular Surgery, Texas Heart Institute, Houston, Tex.

Disclosures: J.S.C. serves as principal investigator for the ongoing clinical trial NCT01920594. Muhammad Aftab has nothing to disclose with regard to commercial support.

Read at The American Association for Thoracic Surgery Aortic Symposium, New York, New York, April 24-25, 2014.

Received for publication April 23, 2014; accepted for publication June 2, 2014

Address for reprints: Joseph S. Coselli, MD, One Baylor Plaza, BCM 390, Houston, TX 77030 (E-mail: jcoselli@bcm.edu).

$0022-5223 / \$ 36.00$

Copyright $₫ 2015$ Published by Elsevier Inc. on behalf of The American Association for Thoracic Surgery

http://dx.doi.org/10.1016/j.jtcvs.2014.12.039 mortality and morbidity. ${ }^{9,10}$ Recent advances in surgical techniques and adjuncts have significantly improved surgical outcomes after open TAAA repair. ${ }^{2,8,11-13} \mathrm{We}$ provide a review of state-of-the-art approaches to renal and visceral protection and report our contemporary experience with open TAAA repair.

For decades, surgeons have developed several perfusion strategies to minimize the ischemic damage to the downstream organs while the aorta is clamped. One strategy is the use of a passive shunt to provide distal aortic perfusion. Its potential advantage lies in providing pulsatile arterial flow to distal organs. This technique is infrequently used because of the popularity of mechanical circulatory support and an inherent inability to conveniently adjust flow rates or distal aortic pressure. Passive shunting to deliver inline mesenteric perfusion combined with cold crystalloid renal perfusion to maintain a core renal temperature at $25^{\circ} \mathrm{C}$ has produced satisfactory results. ${ }^{5}$

With the advancement of extracorporeal circulation technology, two primary approaches have emerged to maintain distal aortic perfusion and provide selective visceral perfusion. The first uses a left heart bypass (LHB) circuit. $^{1,3,7-9}$ LHB can be used to maintain distal perfusion and pressure and be adjusted as needed to sustain stable hemodynamics. We use LHB as a closed circuit with the addition of a reservoir to salvage shed blood. LHB use is associated with an increased incidence 

Abbreviations and Acronyms
LHB $=$ left heart bypass
$\mathrm{TAAA}=$ thoracoabdominal aortic aneurysm

of postoperative renal failure ${ }^{14}$ and isothermic visceral and renal perfusion ${ }^{15}$ was a concern in some initial studies. Jacobs and associates ${ }^{16}$ postulated that this may be due to inadequate renal perfusion pressure. They proposed using catheters equipped with pressure channels to maintain the perfusion pressure at $60 \mathrm{~mm} \mathrm{Hg}$ or higher, particularly in patients with chronic hypertension or chronic renal insufficiency (eg, $85 \mathrm{~mm} \mathrm{Hg}$ ).

Various strategies to provide selective visceral perfusion from modified LHB circuits have been described ${ }^{8,12,17}$ in TAAA repair. Hassoun and coworkers ${ }^{8}$ compared the outcomes of either isothermic $\left(37^{\circ} \mathrm{C}\right)$ or cold blood $\left(4^{\circ} \mathrm{C}\right)$ visceral perfusion of all 4 branching arteries. Of the 347 patients studied, $81(23 \%)$ had development of acute renal failure. Similar acute renal failure rates were found among patients receiving the different perfusion strategies; however, a significantly lower in-hospital mortality was found when using cold blood $(27 \%$ vs $56 \%$; $P<.02)$.

In addition, during TAAA repair, full cardiopulmonary bypass may be used with a wide range of protective hypothermia strategies, such as mild $\left(34^{\circ} \mathrm{C}\right)$ to profound $\left(18^{\circ} \mathrm{C}\right)$ systemic hypothermia, during the repair. Partial cardiopulmonary bypass, with 3 roller pumps for femoralfemoral bypass, celiac axis and superior mesenteric artery perfusion, and bilateral renal perfusion, may also be used. ${ }^{18}$ Kulik and colleagues ${ }^{2}$ recently reported their experience with extent I, II, and III TAAA repairs performed with cardiopulmonary bypass and deep hypothermic $\left(22^{\circ} \mathrm{C}\right.$ or lower) circulatory arrest, with a $7 \%$ incidence $(\mathrm{n}=15)$ of new-onset acute renal failure necessitating dialysis out of 218 patients. More than half of these patients receiving dialysis died after multisystem organ dysfunction, but only $4 \%$ of early survivors required temporary dialysis.

Our current approach to renal and visceral protection for repair of TAAA has evolved from the results of 2 of our randomized clinical trials ${ }^{11,12}$ and has been described in recent publications. ${ }^{19,20}$ In the first trial, we compared postoperative renal dysfunction in patients receiving either isothermic blood or cold crystalloid for renal perfusion. ${ }^{11}$ After multivariate analysis, we found that cold crystalloid perfusion independently protected against renal dysfunction. ${ }^{11}$

Subsequently, we compared renal outcomes in patients receiving either cold blood or cold crystalloid for renal perfusion. ${ }^{12} \mathrm{We}$ found no significant difference between patients with regard to renal failure or early death; however, we noted a statistically nonsignificant trend toward less paraplegia in the cold crystalloid group.

Currently, we apply a multimodal approach to renal and visceral protection. We use moderate heparinization $(1 \mathrm{mg} / \mathrm{kg})$ and mild passive hypothermia (nasopharyngeal temperature near $33^{\circ} \mathrm{C}$ ) in all repairs. Whenever there is access to renal artery ostia, we use intermittent cold crystalloid perfusion. Generally, to provide renal perfusion we prefer to use cold crystalloid, rather than cold blood, as it is less cumbersome to use because an LHB circuit is not needed. We add mannitol $(12.5 \mathrm{~g} / \mathrm{L})$ and methylprednisolone $(125 \mathrm{mg} / \mathrm{L})$ to the Ringer's lactate solution, cool the perfusate to $4^{\circ} \mathrm{C}$, and administer it with a separate roller head pump connected to balloon-tip perfusion catheters. An initial bolus of 200 to $300 \mathrm{~mL}$ of cold crystalloid perfusate is administered per kidney, followed by intermittent infusion of 100 to $150 \mathrm{~mL}$ per kidney delivered every 10 to 15 minutes until arterial flow is reestablished. The volume and frequency are adjusted to avoid fluid overload and hypothermia $\left(>32^{\circ} \mathrm{C}\right.$ temperature).

For extent I and II repairs, we routinely use LHB, maintaining the flows at 1.5 to $2.5 \mathrm{~L} / \mathrm{min}$. After the completion of proximal anastomosis, LHB is stopped, and the remaining aortic aneurysm is opened. During reconstruction, the celiac axis and superior mesenteric artery are perfused through balloon perfusion catheters with isothermic blood from the LHB circuit. A continuous selective perfusion with isothermic blood is delivered at a total flow rate of 300 to $500 \mathrm{~mL} / \mathrm{min}$ until the balloon catheters are removed near completion of the visceral anastomosis.

Recent aortic guidelines recommend the use of cold blood or cold crystalloid renal perfusion (class IIB, level of evidence $\mathrm{B})^{21}$; however, the technique and addition of various additives cause this perfusion to vary among centers. A recent study compared the renal perfusion strategy of using cold crystalloid solution enriched with histidine-tryptophan-ketoglutarate with cold Ringer's lactate solution in patients undergoing open TAAA repair. After 1:1 propensity score matching of 42 patients in each group, the observed freedom from acute kidney injury was significantly greater in the histidine-tryptophanketoglutarate group $(38.1 \%)$ than in the Ringer's lactate solution group $(9.5 \% ; P=.002)$, despite longer total renal ischemic time in the former group. ${ }^{22}$ Currently a phase II, randomized, placebo-controlled, double-blind study is in progress to evaluate the role of a hypoxia-inducible factor prolyl-hydroxylase inhibitor in reducing ischemic events in patients undergoing thoracoabdominal and descending thoracic aortic aneurysm repair. ${ }^{23}$

A significant proportion of patients with TAAA have concomitant visceral and renal artery occlusive disease. ${ }^{24}$ To improve blood flow through occluded visceral arteries, endarterectomy may be performed, or balloon-expandable stents may be used. ${ }^{25}$ The experience of Svensson and 
TABLE 1. Techniques of renal and visceral perfusion and outcomes in 1267 patients undergoing open thoracoabdominal aortic aneurysm repair (January 2005-September 2013)

\begin{tabular}{|c|c|c|c|c|c|}
\hline & $\begin{array}{c}\text { All patients } \\
(\mathrm{n}=1267)\end{array}$ & $\begin{array}{c}\text { Extent I } \\
(\mathbf{n}=\mathbf{3 1 9})\end{array}$ & $\begin{array}{l}\text { Extent II } \\
(\mathbf{n}=398)\end{array}$ & $\begin{array}{l}\text { Extent III } \\
(\mathrm{n}=\mathbf{2 6 1}) \\
\end{array}$ & $\begin{array}{r}\text { Extent IV } \\
(\mathbf{n}=\mathbf{2 8 9}) \\
\end{array}$ \\
\hline \multicolumn{6}{|l|}{ Protective technique (no.) } \\
\hline Left heart bypass & $645(51 \%)$ & $262(82 \%)$ & $355(89 \%)$ & $26(10 \%)$ & $2(1 \%)$ \\
\hline Selective celiac or SMA perfusion & $318(25 \%)$ & $37(12 \%)$ & $255(64 \%)$ & $20(8 \%)$ & $6(2 \%)$ \\
\hline Cold crystalloid renal perfusion & $987(78 \%)$ & $121(38 \%)$ & $357(90 \%)$ & $232(89 \%)$ & $277(96 \%)$ \\
\hline Hypothermic circulatory arrest & $28(2 \%)$ & $17(5 \%)$ & $10(3 \%)$ & $1(<1 \%)$ & 0 \\
\hline \multicolumn{6}{|c|}{ Perfusion and ischemic times (min, median and interquartile range) } \\
\hline Left-heart bypass time & $25(19-30)$ & $27(21-31)$ & $23(17-30)$ & $20(17-27)$ & $19(14-23)$ \\
\hline \multicolumn{6}{|l|}{ Right kidney } \\
\hline Total ischemic time & $45(33-58)$ & $45(36-54)$ & $60(51-71)$ & $37(31-46)$ & $33(27-43)$ \\
\hline Unprotected ischemic time & $33(26-43)$ & $24(17-31)$ & $40(33-48)$ & $36(30-44)$ & $33(26-43)$ \\
\hline \multicolumn{6}{|l|}{ Left kidney } \\
\hline Total ischemic time & $49(37-64)$ & $45(36-55)$ & $64(54-79)$ & $44(35-56)$ & $40(30-51)$ \\
\hline Unprotected ischemic time & $37(27-50)$ & $25(17-31)$ & $44(35-56)$ & $42(33-54)$ & $40(30-50)$ \\
\hline \multicolumn{6}{|l|}{ Celiac axis } \\
\hline Total ischemic time & $45(34-58)$ & $45(36-54)$ & $59(50-70)$ & $39(32-47)$ & $33(26-43)$ \\
\hline Unprotected ischemic time & $34(26-43)$ & $24(17-31)$ & $39(32-48)$ & $37(30-46)$ & $33(26-43)$ \\
\hline \multicolumn{6}{|l|}{ Superior mesenteric artery } \\
\hline Total ischemic time & $45(34-58)$ & $45(37-54)$ & $59(50-70)$ & $39(32-47)$ & $33(26-43)$ \\
\hline Unprotected ischemic time & $33(26-43)$ & $24(17-31)$ & $39(32-48)$ & $37(30-46)$ & $33(26-43)$ \\
\hline \multicolumn{6}{|l|}{ Patient-specific adjuncts for renal and visceral vessels (no.) } \\
\hline Endarterectomy & $396(31 \%)$ & $22(7 \%)$ & $110(28 \%)$ & $119(46 \%)$ & $145(50 \%)$ \\
\hline Placement of stent & $159(13 \%)$ & $9(3 \%)$ & $47(12 \%)$ & $44(17 \%)$ & $59(20 \%)$ \\
\hline Endarterectomy or stent or both & $447(35 \%)$ & $27(8 \%)$ & $126(32 \%)$ & $130(50 \%)$ & $164(57 \%)$ \\
\hline \multicolumn{6}{|l|}{ Outcomes (no.) } \\
\hline Acute renal dysfunction & $155(12 \%)$ & $29(9 \%)$ & $66(17 \%)$ & $34(13 \%)$ & $26(9 \%)$ \\
\hline Renal failure requiring dialysis at hospital discharge & $84(7 \%)$ & $10(3 \%)$ & $36(9 \%)$ & $23(9 \%)$ & $15(5 \%)$ \\
\hline Bowel ischemia & $9(1 \%)$ & 0 & $2(1 \%)$ & $5(2 \%)$ & $2(1 \%)$ \\
\hline
\end{tabular}

Total ischemic time is defined as the interval between application of the initial aortic crossclamp and restoration of normal blood flow to a region; unprotected ischemic time is defined as the region's total ischemic time minus the time that region was perfused during left heart bypass or selective visceral or renal perfusion. All the presented data vary significantly depending on the extent of repair $(P \leq .05)$. SMA, Superior mesenteric artery.

associates $^{14,24}$ demonstrated that renal endarterectomy is associated with significantly less renal failure in patients with preexisting renal dysfunction. Additionally, although all 4 of the branching visceral arteries are commonly attached as an island patch, individual small-diameter grafts may be used as necessary to bypass the visceral vessels; this is particularly useful if the left renal artery becomes widely separated from other visceral vessels or if the ostia of other visceral vessels are so far apart that island patch reimplantation would not be appropriate. ${ }^{20}$

The use of visceral stents in treating renal and mesenteric occlusive disease in patients undergoing TAAA repair is a relatively new strategy to enhance visceral perfusion. ${ }^{25}$ Visceral stents are useful in obliterating the false lumen in concomitant aortic dissection, securing the intimal edges after endarterectomy, facilitating the safe placement of balloon catheters, and helping to keep the ostia patent near the patch anastomosis. Although these adjuncts are usually safe and effective, some of the drawbacks include difficultly in safely manipulating a friable arterial wall after endarterectomy, timeconsuming individual branch anastomoses, possibility of vessel perforation or stent migration after the stent deployment, and risk of thrombosis.

Of 1267 contemporary open TAAA repairs, 411 (32\%) involved separate small-diameter grafts for left renal artery bypasses, $192(15 \%)$ for right renal artery bypasses, and $125(10 \%)$ for celiac artery or superior mesenteric artery bypasses. Either endarterectomy or stents were used in $447(35 \%)$ repairs (Table 1). The operative mortality was $8 \%$, similar to that in our previously published reports. Although the overall incidence of acute renal dysfunction was $12 \%$, only $7 \%$ of repairs necessitated dialysis at the time of discharge. The incidence of renal dysfunction was highest after extent II TAAA repair, which correlates with prolonged protected and unprotected renal ischemia times (Table 1). Although bowel ischemia occurred in only 9 $(1 \%)$ patients, it had a substantial attendant mortality of $88 \%$ (8 of 9 patients).

Contemporary protective strategies enable patients to undergo open TAAA repair with substantially fewer renal and visceral ischemic complications than in previous decades. The risk of renal failure, however, especially in extent II and extent III TAAA repairs, remains a concern 
because of the poor long-term prognosis of these patients. Additional studies are needed to identify and improve renal protection strategies for patients undergoing open TAAA repair.

The authors would like to thank Ana María Rodríguez, $\mathrm{PhD}$, a member of the Baylor College of Medicine Michael E. DeBakey Department of Surgery Research Core Team, for her editorial assistance during the preparation of this manuscript.

\section{References}

1. LeMaire SA, Price MD, Green SY, Zarda S, Coselli JS. Results of open thoracoabdominal aortic aneurysm repair. Ann Cardiothorac Surg. 2012;1:286-92.

2. Kulik A, Castner CF, Kouchoukos NT. Outcomes after thoracoabdominal aortic aneurysm repair with hypothermic circulatory arrest. J Thorac Cardiovasc Surg. 2011;141:953-60.

3. Schepens MA, Heijmen RH, Ranschaert W, Sonker U, Morshuis WJ. Thoracoabdominal aortic aneurysm repair: results of conventional open surgery. Eur J Vasc Endovasc Surg. 2009;37:640-5.

4. Di Luozzo G, Geisbüsch S, Lin HM, Bischoff MS, Schray D, Pawale A, et al. Open repair of descending and thoracoabdominal aortic aneurysms and dissections in patients aged younger than 60 years: superior to endovascular repair? Ann Thorac Surg. 2013;95:12-9; discussion 19.

5. Conrad MF, Crawford RS, Davison JK, Cambria RP. Thoracoabdominal aneurysm repair: a 20-year perspective. Ann Thorac Surg. 2007;83:S856-61; discussion S890-2.

6. Crawford ES, Crawford JL, Safi HJ, Coselli JS, Hess KR, Brooks B, et al. Thoracoabdominal aortic aneurysms: preoperative and intraoperative factors determining immediate and long-term results of operations in 605 patients. J Vasc Surg. 1986;3:389-404.

7. Svensson LG, Crawford ES, Hess KR, Coselli JS, Safi HJ. Experience with 1509 patients undergoing thoracoabdominal aortic operations. J Vasc Surg. 1993;17: 357-68; discussion 368-70.

8. Hassoun HT, Miller CC III, Huynh TT, Estrera AL, Smith JJ, Safi HJ. Cold visceral perfusion improves early survival in patients with acute renal failure after thoracoabdominal aortic aneurysm repair. J Vasc Surg. 2004;39:506-12.

9. Wong DR, Parenti JL, Green SY, Chowdhary V, Liao JM, Zarda S, et al. Open repair of thoracoabdominal aortic aneurysm in the modern surgical era: contemporary outcomes in 509 patients. J Am Coll Surg. 2011;212:569-79; discussion 579-81.

10. Achouh PE, Madsen K, Miller CC III, Estrera AL, Azizzadeh A, Dhareshwar J, et al. Gastrointestinal complications after descending thoracic and thoracoabdominal aortic repairs: a 14-year experience. J Vasc Surg. 2006;44:442-6.

11. Köksoy C, LeMaire SA, Curling PE, Raskin SA, Schmittling ZC, Conklin LD, et al. Renal perfusion during thoracoabdominal aortic operations: cold crystalloid is superior to normothermic blood. Ann Thorac Surg. 2002;73:730-8.

12. LeMaire SA, Jones MM, Conklin LD, Carter SA, Criddell MD, Wang XL, et al. Randomized comparison of cold blood and cold crystalloid renal perfusion for renal protection during thoracoabdominal aortic aneurysm repair. J Vasc Surg. 2009;49:11-9; discussion 19 .

13. Schepens M, Dossche K, Morshuis W, Heijmen R, van Dongen E, Ter Beek H, et al. Introduction of adjuncts and their influence on changing results in 402 consecutive thoracoabdominal aortic aneurysm repairs. Eur J Cardiothorac Surg. 2004:25:701-7.

14. Svensson LG, Coselli JS, Safi HJ, Hess KR, Crawford ES. Appraisal of adjuncts to prevent acute failure after surgery on the thoracic or thoracoabdominal aorta. J Vasc Surg. 1989;10:230-9.

15. Safi HJ, Harlin SA, Miller CC, Iliopoulos DC, Joshi A, Mohasci TG, et al. Predictive factors for acute renal failure in thoracic and thoracoabdominal aortic aneurysm surgery. J Vasc Surg. 1996;24:338-44; discussion 344-5.

16. Jacobs MJ, Eijsman L, Meylaerts SA, Balm R, Legemate DA, de Haan P, et al Reduced renal failure following thoracoabdominal aortic aneurysm repair by selective perfusion. Eur J Cardiothorac Surg. 1998;14:201-5.

17. Cinà CS, Irvine KP, Jones DK. A modified technique of atriofemoral bypass for visceral and distal aortic perfusion in thoracoabdominal aortic surgery. Ann Vasc Surg. 1999;13:560-5.

18. Kuniyoshi Y, Koja K, Miyagi K, Uezu T, Yamashiro S, Arakaki K, et al. Selective visceral perfusion during thoracoabdominal aortic aneurysm repair. Ann Thorac Cardiovasc Surg. 2004;10:367-72.

19. Coselli JS, LeMaire SA, Weldon SA. Extent II repair of thoracoabdominal aortic aneurysm secondary to chronic dissection. Ann Cardiothorac Surg. 2012;1: 394-7.

20. de la Cruz KI, LeMaire SA, Weldon SA, Coselli JS. Thoracoabdominal aortic aneurysm repair with a branched graft. Ann Cardiothorac Surg. 2012;1: 381-93.

21. Hiratzka LF, Bakris GL, Beckman JA, Bersin RM, Carr VF, Casey DE Jr, et al American College of Cardiology Foundation/American Heart Association Task Force on Practice Guidelines; American Association for Thoracic Surgery; American College of Radiology; American Stroke Association; Society of Cardiovascular Anesthesiologists; Society for Cardiovascular Angiography and Interventions; Society of Interventional Radiology; Society of Thoracic Surgeons; Society for Vascular Medicine. ACCF/AHA/AATS/ACR/ASA/SCA/ SCAI/SIR/STS/SVM guidelines for the diagnosis and management of patients with thoracic aortic disease: a report of the American College of Cardiology Foundation/American Heart Association Task Force on Practice Guidelines, American Association for Thoracic Surgery, American College of Radiology, American Stroke Association, Society of Cardiovascular Anesthesiologists, Society for Cardiovascular Angiography and Interventions, Society of Interventional Radiology, Society of Thoracic Surgeons, and Society for Vascular Medicine. Circulation. 2010;121:e266-369. Erratum in: Circulation. 2010;122:e410.

22. Tshomba Y, Kahlberg A, Melissano G, Coppi G, Marone E, Ferrari D, et al. Comparison of renal perfusion solutions during thoracoabdominal aortic aneurysm repair. J Vasc Surg. 2014;59:623-33.

23. ClinicalTrials.gov. Identifier NCT01920594. Study of GSK1278863 to reduce ischemic events in patients undergoing thoracic aortic aneurysm repair. Bethesda (MD): National Library of Medicine (US); 2013. Available at: http:// clinicaltrials.gov/ct2/show/study/NCT01920594. Accessed April 14, 2014.

24. Svensson LG, Crawford ES, Hess KR, Coselli JS, Safi HJ. Thoracoabdominal aortic aneurysms associated with celiac, superior mesenteric, and renal artery occlusive disease: Methods and analysis of results in 271 patients. J Vasc Surg. 1992;16:378-89; discussion 389-90.

25. LeMaire SA, Jamison AL, Carter SA, Wen S, Alankar S, Coselli JS. Deployment of balloon expandable stents during open repair of thoracoabdominal aortic aneurysms: a new strategy for managing renal and mesenteric artery lesions. Eur J Cardiothorac Surg. 2004;26:599-607. 